Inhaltsverzeichnis / Table de matières

Vorwort

Préface

Autorenverzeichnis/Liste des auteurs

Richterliche Eingriffe in den Vertrag -

Einleitende rechtsvergleichende Anmerkungen

Peter Jung

Die Rolle der Gerichte im nationalen, trans- und supranationalen Vertragsrecht Le rôle du juge en droit national, transnational et supranational des contrats

Richterliche Eingriffe in Verträge in der Praxis des schweizerischen Bundesgerichts

Kathrin Klett

Le rôle du juge dans les codifications doctrinales internationales du droit des contrats

Claude Witz

Le rôle du juge dans le droit dérivé européen des contrats Evelyne Tichadou

Gesetzesbindung und Vertragsbindung des Gerichts Le juge entre loi et contrat

Die gesetzliche Rechtfertigung des richterlichen Vertragseingriffs

Ulrike Babusiaux

La qualification du contrat de travail par le juge: réflexions comparatives à partir des droits français et hellénique

Barbara Palli 
Kriterien der Vertragstypenzuordnung durch den EuGH: Der Kauf einer noch herzustellenden Sache in europäischer Perspektive Saskia Kümmerle

La décision du juge suisse sur la nature impérative de la loi Ariane Morin

Der Entscheidungsspielraum des Gerichts bei der Bestimmung der Ungültigkeitsfolgen

Davide Giampaolo/Claire Huguenin

Gerichtliche Bestimmung des vertraglichen Pflichtenprogramms La détermination judiciaire des obligations contractuelles

Le contrôle des prestations dans les contrats portant sur des droits de propriété intellectuelle - Étude de droit comparé franco-suisse Jean-Luc Piotraut

Die Pflichtenstruktur des Maklervertrags in BGB und DCFR Methodologische, historische und rechtsvergleichende Skizzen

Chris Thomale

Le principe d'égalité de traitement des salariés en droit français Jean-Michel Gasser

Gerichtliche Kontrolle des Vertragsinhalts Le contrôle matériel judiciaire du contenu du contrat

Contrôle par le juge du contenu des conditions générales de contrat - Approches plurielles d'une question récurrente

Liliane Nau

Die richterliche Inhaltskontrolle Allgemeiner Geschäftsbedingungen im schweizerischen Recht: Ein rückblickender Ausblick in die Zukunft Thomas Probst

Le contrôle prétorien du contrat de société en faveur des actionnaires investisseurs

Andra Cotiga 
Richterliche Kontrolle von Bürgschaften naher Angehöriger

Christiana Fountoulakis

La «convergence parallèle» de l'office des juges français et italiens en matière de rupture de contrat de travail pour motif économique

Raphaël Dalmasso

\section{Schlussbemerkung -}

Rapport de synthèse

Schlussbemerkung zur Tagung "Richterliche Eingriffe in den Vertrag"

Ernst A. Kramer

\section{Tagungsberichte - \\ Comptes rendus}

Tagungsbericht: Richterliche Eingriffe in den Vertrag

Thomas Raff

Compte rendu du colloque portant sur «l'intervention du juge dans le contrat»

Violaine Kocher

Index

Gesetzesregister / Articles de loi 
